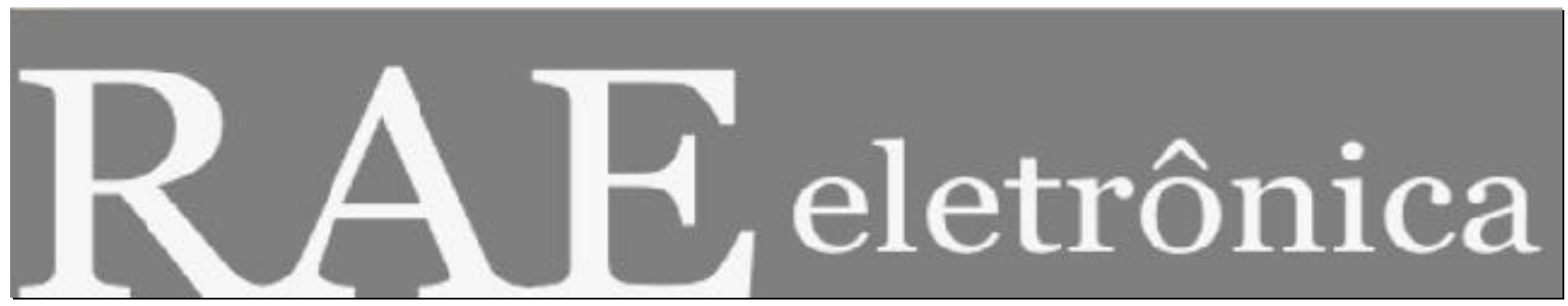

\title{
PARADOXOS CULTURAis NA GESTÃO DE PESSOAS: CULTURA E CONTEXTO EM UMA COOPERATIVA AGRO-INDUSTRIAL
}

Por:

\section{Isabella Vasconcelos}

\section{André Ofenhejm Mascarenhas}

Roberto M. Protil

RAE-eletrônica, v. 3, n. 1, Art. 11, jan./jun. 2004

http://www.rae.com.br/eletronica/index.cfm?FuseAction=Artigo\&ID=1993\&Secao=ORGANIZA\&Vol ume $=3 \&$ Numero $=1 \&$ Ano $=2004$

CCopyright, 2004, RAE-eletrônica. Todos os direitos, inclusive de tradução, são reservados. É permitido citar parte de artigos sem autorização prévia desde que seja identificada a fonte. A reprodução total de artigos é proibida. Os artigos só devem ser usados para uso pessoal e nãocomercial. Em caso de dúvidas, consulte a redação: redacao@ rae.com.br.

A RAE-eletrônica é a revista on-line da FGV-EAESP, totalmente aberta e criada com o objetivo de agilizar a veiculação de trabalhos inéditos. Lançada em janeiro de 2002, com perfil acadêmico, é dedicada a professores, pesquisadores e estudantes. Para mais informações consulte o site www.rae.com.br/eletronica.

\section{RAE-eletrônica}

ISSN 1676-5648

(C2004 Editora: Fundação Getulio Vargas - Escola de Administração de Empresas de São Paulo

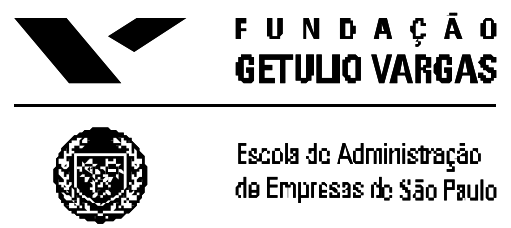




\title{
PARADOXOS CULTURAis NA GESTÃo DE PESSOAS: CULTURA E CONTEXTO EM UMA COOPERATIVA AGRO-INDUSTRIAL
}

\begin{abstract}
RESUMO
O tema paradoxos organizacionais vem ganhando espaço no estudo das organizações. Em uma perspectiva dialética de evolução social, este conceito refere-se à realidade socialmente construída pelos atores, que representam os sistemas complexos nos quais estão inseridos em torno de duas percepções contraditórias que passam a orientar a sua ação. A partir das premissas do interacionismo simbólico, conceituamos e discutimos neste artigo um paradoxo cultural na gestão de pessoas por meio de um estudo etnográfico em uma cooperativa agro-industrial. Partimos da visão da organização como um complexo contexto cultural, formado pelo agrupamento de diversos sistemas de significação. Neste contexto, analisamos os conflitos gerados por interpretações divergentes de práticas sociais, resultado de repertórios culturais distintos, que causaram percepções contraditórias do sistema social. Discutimos estes conflitos em termos de sua influência na evolução do sistema organizacional. Ao final do artigo, fazemos algumas considerações acerca dos estudos futuros sobre o tema.
\end{abstract}

\begin{abstract}
The theme of organizational paradoxes has gained importance in recent studies of organizations. From a dialectical perspective of social evolutio $\mathrm{n}$, this concept refers to a socially constructed reality where participants represent the complex systems in which they find themselves through two contradictory perceptions, that guide their attitudes. From the premisses of the Symbolic Interactionism, we discuss in this article the concept of cultural paradox in human resources management through an ethnographical study in an agro-industrial cooperative. We adopt the idea that an organization is a complex cultural context formed by a group of systems of meanings. In such a context, we analyze the conflicts that occur because of distinct interpretations of social practices, result of different cultural repertories, causing contradictory perceptions of the social system. We discuss these conflicts in terms of their influence in the evolution of the organizational system. At the end, we make some comments about future studies on the theme.
\end{abstract}

\section{PALAVRAS-CHAVE}

Gestão de pessoas, paradoxos organizacionais, cultura organizacional, estudos organizacionais.

\section{KEY-WORDS}

Human resource management, organizational paradoxes, organizational culture, organizational studies. 


\section{ORGANIZAÇÕES - PARADOXOS CULTURAIS NA GESTÃO DE PESSOAS: CULTURA E CONTEXTO EM UMA \\ COOPERATIVA AGRO-INDUSTRIAL \\ Isabella Vasconcelos - André Ofenhejm Mascarenhas - Roberto M. Protil}

\section{INTRODUÇÃO}

O estudo dos paradoxos organizacionais tem sido um tema relevante em teoria das organizações. Uma revisão da literatura mostra que Merton, Selznick, Blau e Scott e outros autores clássicos que estudaram as disfunções da burocracia, desde os anos 50, já analisavam o fato de que a administração possui alguns paradoxos básicos próprios à toda ação social. Este tema voltou à agenda tendo em vista que o atual contexto sócio-econômico enfrentado pelas organizações reforça as contradições entre os modelos professados e os modelos efetivamente praticados nas organizações. Neste trabalho, partimos de uma visão dialética de evolução social para conceituarmos os paradoxos como realidades socialmente construídas, a partir de percepções simplificadas dos atores sociais, que, ao tentarem atribuir sentido à sua experiência, representam os sistemas complexos nos quais estão inseridos em torno de duas percepções contraditórias que passam a orientar a sua ação (Merton, 1950; Blau e Scott, 1970; Selznick, 1955; Lewis, 2000; Vasconcelos e Vasconcelos, 2001; Eisenhardt, 2000; Barbosa, Ferraz, Lopes, 2002; Capelle e Brito, 2002; Alves, 2002; Faria e Meneguetti, 2001; Motta e Vasconcelos, 2002; Festinger, 1957).

Parte significativa dos estudos atuais sobre este tema adota os princípios do interacionismo simbólico ao tratar os paradoxos como contradições e fenômenos que atrapalham a construção de sentido comum pelo grupo organizacional e logo dificultam sua ação. Ao assumirmos esta linha de pensamento, devemos entender as organizações como culturas. Entendê-las desta maneira implica dizermos que os padrões de cultura organizacional são a base para a interpretação, a valoriza ção e o estabelecimento de todas as práticas sociais em uma organização, já que a partir destes padrões os seus membros organizam sua interação social. Os trabalhos que partem dos princípios deste paradigma de pesquisa abordam temas como as dificuldades dos indivíduos em conciliar papéis sociais diferentes e contraditórios, que exigem ao mesmo tempo posturas, éticas, vocabulário e posicionamentos opostos, e as contradições que dificultam a comunicação, impedindo então a criação de um sentido comum para a ação organizacional.

Associando os princípios do interacionismo simbólico à visão dialética de evolução social, pretendemos neste artigo avançar a discussão sobre os paradoxos organizacionais conceituando e analisando os paradoxos culturais na gestão de pessoas. Este tipo de paradoxo surge quando práticas sociais são interpretadas a partir de repertórios culturais distintos na organização, o que causa percepções divergentes da realidade. Tratamos também dos potenciais conflitos na gestão de pessoas que aparecem quando os indivíduos ou grupos se deparam com este tipo de paradoxo, e analisamos estes conflitos em termos de sua influência na evolução do sistema organizacional.

Iniciamos o estudo por meio de uma revisão teórica. Apresentamos o conceito de paradoxo organizacional em uma perspectiva dialética de evolução social e a visão da organização como um complexo contexto cultural. Os princípios dos modelos instrumental e político de gestão de pessoas são discutidos a seguir. Estes modelos são encontrados em contextos culturais distintos, respectivamente marcados pela hierarquização das relações e pela negociação e consenso. Estes conceitos são essenciais para nossa discussão sobre os paradoxos culturais na gestão de pessoas, caracterizados após a apresentação de dados etnográficos. Estes dados são interpretados a partir de reflexões sobre as relações entre subculturas organizacionais e determinados modelos de gestão de pessoas. Na parte final deste artigo, fazemos ainda breves considerações sobre estudos futuros acerca destes paradoxos. 


\section{PARADOXOS ORGANIZACIONAIS - UMA PERSPECTIVA DIALÉTICA DE ANÁLISE SOCIAL}

O tema paradoxos organizacionais na literatura estrangeira e nacional tem sido analisado por uma grande quantidade de textos, em diferentes correntes de pesquisa. (Eisenhardt 2000; Lewis, 2000; Vasconcelos, Motta, Pinochet, 2003). Lewis (2000) mostra como, a fim de atribuir sentido e compreender os sistemas complexos e ambíguos nos quais estão inseridos, os indivíduos e grupos nas organizações têm a tendência de polarizar suas percepções em torno de elementos contraditórios e inconsistentes. A partir disso, começam a agir em função desta percepção polarizada. Os paradoxos são, desta maneira, realidades socialmente construídas a partir das percepções polarizadas dos atores sociais, que, ao atribuírem sentido à sua experiência, representam a realidade complexa na qual estão inseridos através de percepções contraditórias que passam a orientar a sua ação. A autora afirma que os paradoxos podem assumir uma variedade de elementos contraditórios e incoerentes nas organizações, como perspectivas, sentimentos, interpretações, identidades ou práticas (Lewis, 2000).

Este tema envolve uma concepção dialética da evolução social. Hegel (1941) afirma que a realidade é o fluxo eterno dos contraditórios. Assim, termos paradoxais não são dois positivos excludentes, mas dois predicados contraditórios do mesmo sujeito (Sabelis, 1996). Segundo a corrente filosófica hegeliana, a contradição dialética revela um sujeito que surge, se manifesta e se transforma graças à contradição de seus predicados, tornando-se outro do que era pela negação interna dos mesmos. Trata-se do processo de tese-antítese e síntese. Em lugar da contradição ser o que destrói o sujeito, ela é o que o movimenta e o transforma, fazendo-o síntese ativa de todos os predicados postos e negados por ele (Myeong-Gu e Creed, 2002).

Uma perspectiva dialética de análise estuda a construção social da realidade através do construto social, das contradições geradas por estes, e da transformação do sistema social por meio da práxis. A denominação construto social refere-se ao sistema social produzido a partir de interações políticas dos indivíduos em busca de seus interesses específicos. Padrões culturais e sociais emergem destas interações e são institucionalizados no sistema social recém-formado. Este sistema social ou construto é composto por diversos grupos e estruturas interconectadas de forma mais ou menos autônoma, que produzem também padrões culturais e sociais específicos (Poole e Van de Ven e 1989). Um exemplo seria um sistema organizacional formado por regras, normas, padrões de comportamento gerais, porém contendo subgrupos e subsistemas cada qual com suas micro-dinâmicas ou subculturas particulares. As rupturas e inconsistências nos diversos subgrupos do sistema organizacional geram ambigüidades e contradições perceptivas, que impulsionam a práxis social

A práxis é a livre e criativa reconstrução dialética do sistema social, uma vez que a partir das contradições perceptivas os subgrupos organizacionais podem se movimentar no sentido de questionar o sistema e as regras presentes e agir politicamente no sentido de modificá-las (Davis, Maranville, Obloj, 1995). Os indivíduos insatisfeitos com as regras vigentes são agentes de mudança em potencial. Este processo, entretanto, gera tensões no sistema social. No campo de psicodinâmica organizacional, autores como de Vries (1995), Frost e Robinson (1999), Enriquez (1991), entre outros, analisam estes efeitos dos paradoxos orga nizacionais e sustentam que os grupos de atores sociais desenvolvem reações defensivas que aumentam o nível de stress no sistema organizacional As contradições perceptivas e paradoxos, que incomodam estes agentes, geram portanto a energia para a transformação do construto social. 


\section{A ORGANIZAÇÃO COMO UM CONTEXTO CULTURAL E A ABORDAGEM DE DIFERENCIAÇÃOO}

Podemos caracterizar a organização como um contexto cultural. Para fazê-lo, usaremos a abordagem antropológica interpretativa e algumas de suas críticas mais importantes. Cultura são conjuntos de representações em cujos contextos os eventos, ações, objetos, expressões e situações ganham significados específicos. Cultura são os padrões de significação que conferem sentido à interação humana. Geertz, o mais importantes expoente da antropologia interpretativa, defende um conceito de cultura essencialmente semiótico. Como diz Geertz (1989, p. 15), "acreditando, como Max Weber, que o homem é um animal amarrado a teias de significados que ele mesmo teceu, assumo a cultura como sendo estas teias e sua análise". Metaforicamente, o autor entende a cultura como um texto ou um conjunto de textos lidos pelos atores sociais, com os quais eles dão sentidos a suas ações sociais (Jaime Júnior, 2002).

Ao discutir a proposta interpretativa de Geertz, Thompson (1995) e Fischer (1985) sustentam ainda que os fenômenos culturais estão inseridos em contextos e processos socialmente estruturados, implicados em relações de conflito e poder. Segundo estes autores, os indivíduos estão inseridos em esferas distintas da estrutura social, diferentes posições na sociedade, e possuem, portanto, capitais econômicos, culturais e sociais diferentes. Desta maneira, eles constroem interpretações distintas dos fenômenos simbólicos já que possuem diferentes percepções, biografias, interesses e papéis. Thompson argumenta que os fenômenos culturais devem ser analisados levando-se em conta os contextos sociais estruturados, dentro dos quais eles são produzidos e interpretados, já que os atores sociais lêem o mundo a partir da posição que ocupam na estrutura social. Utilizando-se da metáfora dos textos de Geertz, Thompson diz que, como os textos literários, os leitores constroem interpretações distintas por possuírem conhecimentos prévios diferentes.

Barbosa discute este conceito. Segundo ela, a cultura são regras de interpretação da realidade, sistemas de classificação que permeiam os grupos sociais e instauram os domínios da experiência humana (Barbosa, 1999). Estas regras e sistemas criam condições para o compartilhamento de sentidos e representações comuns nos grupos sociais, e são o substrato a partir do qual a interação humana ganha significados específicos. Como coloca a autora, a cultura deve ser entendida como "redes" de significados que "se combinam e se recombinam, gerando sempre novos padrões que formam os contextos nos quais se desenrolam e se tornam significativas as ações sociais" (Barbosa, 1999, p. 142). Estas redes podem ser entendidas como sistemas subjacentes a todas as práticas cotidianas mos grupos, dando sentido a todas elas.

O conceito de cultura descrito brevemente acima pode ser aplicado aos contextos organizacionais. Numa organização, a cultura pode ser definida como os conjuntos de representações e estruturas de significação renegociadas constantemente pelos membros da organização a partir dos quais eles dão significado às suas ações, no contexto de sua interação social. As idéias apresentadas acima nos permitem perceber que os diversos conjuntos de representações encontrados dentro de uma organização relacionam-se de forma estreita aos contextos sócio-culturais nos quais os seus membros se inserem. Isso acontece porque estes grupos sociais formam sua concepção de mundo a partir de suas experiências em diversas esferas da vida cotidiana e estão inseridos de forma desigual na estrutura social. Desta maneira, grupos sociais imersos em contextos sócio-culturais distintos interagem segundo padrões distintos. Esta é uma das chaves para se explicar o aparecimento de subculturas em uma organização. 
O conceito de cultura organizacional apresentado acima é utilizado como base para pesquisas que adotam uma abordagem de diferenciação, que tem seu foco nas manifestações culturais que são interpretadas de maneira inconsistente entre os grupos organizacionais. Martin (2002) mostra que, em uma abordagem de diferenciação, a cultura organizacional é entendida como a união de diversas subculturas nas quais as manifestações culturais podem ser interpretadas de maneira inconsistente. Estes grupos distintos interagem no sistema organizacional a partir de seus sistemas próprios de significação e sensos de prioridade. Estas subculturas podem ser entendidas como contextos culturais distintos encontrados dentro das organizações. São conceituadas e classificadas na maioria dos estudos por meio de dimensões como a distância ao poder, categorias profissionais, gênero, identidades demográficas etc (Martin, 1992 e 2002).

Martin (2002) argumenta, a partir de amplo levantamento bibliográfico, que esta abordagem não é a mais difundida entre os pesquisadores do tema. Esta seria a abordagem de integração, que se foca nas manifestações culturais que são interpretadas de maneira consistente entre os grupos. A adoção da abordagem de integração implica na elaboração de visões consensuais da cultura organizacional. Desta forma, a cultura é o que é claro e compartilhado pelos membros da organização. Nesta abordagem a ambigüidade é excluída.

Ao adotarmos a abordagem de diferenciação para a análise cultural, as diversas vozes nas organizações não são silenciadas. Percebe-se então que a cultura organizacional não pode ser considerada um único sistema fechado de valores que serve como roteiro para a ação naquele contexto. Diferentemente, este conceito de cultura organizacional diz respeito a um complexo agrupamento de conjuntos de significados criados e recriados constantemente, segundo os quais os indivíduos, inseridos em contextos sociais estruturados, dão sentido à sua experiência e organizam sua interação social. Podemos dizer que este complexo agrupamento de padrões culturais é a base para o estabelecimento e interpretação de todas as práticas sociais em uma organização, já que a partir destes padrões os seus membros organizam sua interação social. Isso quer dizer que os diversos sistemas de representações, negociados dentro dos grupos e entre eles, são a base para que as práticas sociais ganhem significados específicos, sejam compreendidas e valorizadas de maneiras específicas (Martin, 1992; Fleury, 1996).

\section{CONTEXTO CULTURAL E OS MODELOS INSTRUMENTAL E POLÍTICO DE GESTÃO DE PESSOAS}

A partir da discussão da organização como um contexto cultural desenvolvida acima, podemos destacar dois modelos de gestão de pessoas e sua relação com determinados contextos culturais. É importante destacar neste momento o conceito de modelo de gestão de pessoas adotado. Este conceito não se restringe ao caráter instrumental da gestão de pessoas mas diz respeito às diferentes lógicas que influenciam o comportamento na organização. $O$ modelo de gestão de pessoas, desta maneira, sistematiza componentes políticos, ideológicos, sociais e comportamentais que orientam a ação e a decisão no contexto organizacional. Os modelos apresentados a seguir foram identificados por meio de uma grande pesquisa realizada nos anos 90 por pesquisadores na França e nos Estados Unidos. Foram feitos o recenseamento e a sistematização das práticas e modelos didáticos através dos quais as organizações e indivíduos representam sua experiência. Cada um dos modelos de gestão de pessoas, entretanto, deve ser entendido como uma categoria da qual cada contexto particular se aproxima mais ou menos, dependendo das particularidades culturais que são a base do sistema social. Trata-se de tipos ideais ${ }^{i}$, isto é, modelos que se aproximam mais ou menos das realidades empíricas, mas que serão utilizados como ferramenta para nossa análise (Brabet, 1996). 
Estes modelos refletem idéias consagradas no pensamento administrativo, e têm pressupostos diferentes. O "Modelo Instrumental de Recursos Humanos" reflete o pensamento da Escola Clássica de Administração, com alguns aperfeiçoamentos, e é encontrado em contextos em que o formalismo, a autoridade e a rigidez permeiam as relações sociais (Trootings, Gustavsen e Hethy, 1989). O Modelo Instrumental de gestão de pessoas caracteriza-se pelo pressuposto da existência de uma "racionalidade superior" na organização. A gestão de pessoas segundo este modelo pressupõe a idéia de que a empresa é considerada um instrumento racional de produção, cuja estratégia é definida por seus diretores em função das pressões do mercado. A administração de recursos humanos tem a função de implantar esta estratégia buscando a maximização do resultado econômico, uma vez que em tese toda a comunidade organizacional será beneficiada. Dentro deste modelo, os empregados são considerados seres utilitaristas e condicionáveis, já que seria possível levá-los a adotarem os comportamentos esperados, medindo-se às respostas aos estímulos dados.

Este modelo é baseado no argumento de que a sociabilidade harmônica gera a eficiência econômica e vice-versa, o que significa que o conflito é disfuncional e prejudicial ao sistema social. Procura-se evitar os conflitos ou resolvê- los rapidamente, pois se considera que um ambiente harmônico, sem contestações ou resistências e com um alto grau de conformidade por parte dos atores sociais favorece a produtividade na empresa. Os debates são considerados desnecessários e as decisões devem ser tomadas pelos dirigentes. Não se fala em atores sociais, mas em agentes. Dentro deste modelo de gestão, a organização deve fomentar a construção da dinâmica social considerada mais adequada aos seus objetivos. A "racionalidade superior", desta forma, refere-se ao pressuposto de passividade dos ditos agentes organizacionais frente à administração, que possui as capacidades e visão do mundo adequada para conduzi- los em direção ao sucesso geral.

Diferentemente, o "Modelo Político de Recursos Humanos" reflete os princípios da Democracia Industrial e é baseado principalmente nos trabalhos de Herzberg e dos pesquisadores do Instituto Tavistock de Londres. Este modelo é típico de contextos nos quais valores como o consenso, a diversidade e igualdade de direitos dos membros da organização permeiam as relações sociais. $\mathrm{O}$ modelo político diferencia-se do anterior pela importância dada à dimensão política na organização e pela incorporação da idéia de conflito e divergência tendo em vista os diferentes interesses dos atores organizacionais. Reconhece-se a existência de várias lógicas de ator e critérios de ação válidos, tendo em vista o modelo da racionalidade limitada de Simon, segundo o qual toda a racionalidade é relativa ao ator social que decide, não existindo uma racionalidade absoluta inquestionável (Simon, 1947; Simon, 1955). O conceito da racionalidade limitada revela que toda decisão é contingente e deve ser analisada dentro do contexto social do momento da tomada de decisão

Neste modelo, os indivíduos são percebidos como atores participando e influenciando as mudanças, nos seus diversos níveis de atuação. Neste caso, um bom gerente tem como objetivo obter a coesão integrando os interesses particulares dos diferentes grupos de atores visando a obtenção de uma solução negociada junto à direção da empresa (Beer e Wakon e al. 1985; Brabet, 1993). A organização é um espaço de jogo estratégico entre estes atores sociais, no qual a negociação é vista como necessária à boa implantação das estratégias.

Desta maneira, cada um destes modelos reflete princípios diferentes que influenciaram a teoria organizacional em determinados momentos, e é encontrado em contextos organizacionais nos quais os indivíduos compartilham padrões de significado distintos (Brabet, 1993). Apesar destes modelos ainda não terem sido validados no Brasil em uma pesquisa abrangente, o estudo de caso deste artigo permite ilustrar esta tipologia na medida em que a representação que os grupos de atores organizacionais fazem 
de sua experiência pode ser classificada em um destes modelos, que está institucionalizado como referência local válida (Vasconcelos e Vasconcelos, 2002). A partir deste estudo de caso, podemos discutir o conceito de paradoxo cultural na gestão de pessoas.

\section{METODOLOGIA DE PESQUISA}

Esta pesquisa foi realizada através de uma observação participante na organização estudada que durou aproximadamente 6 meses, em período parcial, ao final do ano de 1998. Como princípio de coleta de dados, seguimos a metodologia etnográfica e não adotamos uma hipótese fechada a priori. Definimos as premissas básicas de observação e os fatos que gostaríamos de abordar de maneira que pudéssemos apreender, sem idéias preconcebidas, as categorias sociais relevantes e os seus significados socialmente construídos (Rada e Velasco, 1997). Neste sentido, a compreensão do fracasso eleitoral do dirigente da organização foi o direcionador das observações e entrevistas. Era nosso objetivo apreender as categorias sociais relevantes, reconstruir as experiências dos atores e os significados socialmente construídos para chegarmos a uma interpretação possível sobre o fato estudado.

Foram entrevistadas 30 pessoas (direção, consultores e cooperados) através de entrevistas abertas que duraram uma hora e meia em média. Foram entrevistados em número proporcional indivíduos pertencendo aos principais gupos organizacionais descritos no caso. As entrevistas, que não foram gravadas, foram caracterizadas pela reconstrução das experiências dos atores por meio da sugestão de temas e estímulo à livre construção das idéias e argumentos pelos atores relevantes. Os procedimentos para o levantamento de dados incluíram ainda a inserção e participação do pesquisador em eventos organizacionais como reuniões administrativas, negociações, e outras atividades a partir das quais se pode aprender sobre a dinâmica social ma organização. Analisaram-se também documentos da empresa a fim de complementar as informações obtidas através da observação participante e das entrevistas.

Considera-se nesta metodologia que o observador externo deve procurar identificar as formas de expressão características da visão de mundo de cada grupo organizacional. Para tanto, o pesquisador deverá observar:

- A prática de ritos coletivos;

- A perpetuação de mitos ou histórias sobre a organização, em particular sobre aqueles que detém o poder;

- A existência de tabus;

- As normas de comportamento e como cada grupo reage às mesmas;

- Os valores e a ética que orientam a ação concreta dos diversos grupos, muitas vezes valores opostos aos divulgados oficialmente;

- As comunicações oficiais e os símbolos associados às mesmas.

Linda Smircich trata deste tipo de pesquisa salientando que o conhecimento gerado por esta metodologia pode ser classificado como "conhecimento subjetivo". Neste tipo de método, o que caracteriza a ciência positivista, ou seja, as relações do tipo sujeito/objeto são substituídas por relações do tipo sujeito/sujeito, onde o pesquisador focaliza sua atenção nos significados partilhados intersubjetivamente. Este método tem como pressuposto que o conhecimento não é independente do 
pesquisador. Este útimo apreende as significações das ações dos grupos através da sua interação com os membros da organização e assim ele tem uma visão global dos significados e imagens partilhadas pelos membros dos grupos organizacionais. É importante ressaltar que um estudo de caso traz informações válidas permitindo aprofundar certos aspectos de uma teoria ou refutá-la, mas, por não obedecer a técnicas estatísticas, não se pode fazer afirmações genéricas (Smircich,1983a; Smircich, 1983b).

\section{ESTUDO DE CASO: A HISTÓRIA DA COOPERATIVA AGRO-INDUSTRIAL}

A cooperativa estudada, constituída em 1951 no Paraná, foi criada para representar os interesses econômicos, políticos e sociais de colonos europeus imigrantes, que formaram uma comunidade agrária. Para compreendermos o contexto cultural destes imigrantes, é necessário fazermos uma breve retrospectiva histórica. Descendentes de europeus que haviam colonizado entre os séculos XVII e XVIII extensas áreas do vale do rio Danúbio, estas famílias eram organizadas em pequenos povoados e viviam há mais de 200 anos transmitindo de geração em geração valores e tradições próprias à sua cultura, a qual era baseada em pequenas comunidades onde a sobrevivência dependia da cooperação e da ajuda entre seus membros, que se organizavam através da auto-gestão.

A autoridade era tradicional e a comunidade regulada através dos valores e hábitos transmitidos de pai para filho. Os colonos eram muito apegados à sua terra e tradições. No entanto, devido à segunda guerra mundial, temendo o avanço do exército soviético e temendo represálias políticas e étnicas, estes colonos foram obrigados a abandonar entre 1943 e 1944 as terras desta fértil região da Europa central nas quais suas famílias tinham vivido durante mais de dois séculos. Tendo em vista um programa de colonização coordenado pelo governo brasileiro em conjunto com a Cruz Vermelha Internacional, estes colonos (aproximadamente 2.000 famílias) imigraram para o Brasil e foram assentados em 5 vilas.

Estes imigrantes tinham em comum padrões culturais fortes que tinham sido transmitidos de geração para geração. Eles organizaram a sua comunidade no Brasil em torno dos mesmos padrões culturais que tinham herdado de seus antepassados - um sentido forte de comprometimento com a comunidade, autogestão, igualdade de direitos e a noção de que uma família deveria colaborar com a outra de forma organizada a fim de minimizar as dificuldades de todos.

Após quase 50 anos de atuação a cooperativa agro-industrial em questão é hoje uma das 500 maiores empresas brasileiras segundo o levantamento anual da revista Exame, com um faturamento de aproximadamente $\mathrm{R} \$ 280$ milhões. Em seu quadro social e funcional constam mais de 500 associados e 900 funcionários, sendo que $100 \%$ dos associados apresentam fidelidade absoluta, ou seja toda compra de insumos e toda venda da produção agrícola é feita nos entrepostos da cooperativa. Em 1998 a organização cultivava trigo, cevada, aveia, milho e soja, além de produzir carne suína. $\mathrm{Na}$ área industrial conta com um moinho, fabrica de rações, uma industria de processamento de soja e uma maltaria.

\section{ESTUDO DE CASO: SUCESSÃO E IMPLANTAÇÃO DO SISTEMA ERP NA COOPERATIVA AGRO-INDUSTRIAL}

Durante 28 anos, a cooperativa tinha sido dirigida por um líder que fazia parte do grupo dos fundadores. Este homem tinha imigrado para o Brasil com 18 anos e tomado parte do processo de criação da comunidade de imigrantes e, posteriormente, da cooperativa. Líder carismático e 
empreendedor com grande habilidade política e capacidade de negociação, tornourse em pouco tempo o representante dos valores da comunidade, a autogestão, a igualdade de direitos e o consenso.

Os padrões culturais dos imigrantes estavam fortemente representados na cultura organizacional da cooperativa onde, sob influência do diretor-presidente, as soluções a serem adotadas eram decididas após um processo político do qual os representantes dos cooperados participavam. Tratava-se de um sistema político com práticas semi-estruturadas. Por meio da articulação e negociação com os atores sociais relevantes na administração da cooperativa, e com a anuência do Conselho Administrativo, que representava os cooperados, o diretor-presidente garantia a segurança e a estabilidade daquele contexto.

No ano de 1994, o diretor-presidente morreu subitamente. Ao contrár io do diretor-presidente, o vicepresidente era uma pessoa inexpressiva politicamente, mas por ser um bom agricultor e advindo de uma família numerosa e bem representada na comunidade tinha sido designado à função. Sempre esteve na sombra da administração, ou seja, tinha pouca ou nenhuma influencia sobre a administração e praticamente não decidia nada. Apesar de sua posição na organização estudada, o grande salto em sua carreira se deu quando no inicio dos anos noventa foi criada na região uma central de cooperativas formada por cinco outras instituições. Nesta oportunidade foi empossado como presidente nesta central de cooperativas, pois era o representante da instituição majoritária, e passou a acumular os dois cargos: vice-presidente na cooperativa estudada e presidente na central de cooperativas. Nesta oportunidade conheceu duas figuras importantes em sua carreira política, o diretor comercial e o assessor de $\mathrm{RH}$ desta central.

Quando do falecimento do diretor-presidente, os cooperados, após 27 anos de uma liderança carismática, deveriam eleger um novo presidente. Devido ao choque, à desorientação pela perda do líder e à falta de lideranças, a comunidade optou em eleger o então vice-presidente para um mandato determinado, na esperança que não houvesse descontinuidade na condução da cooperativa. Logo ao tomar posse, o vice-presidente, agora novo presidente, procurou se cercar de pessoas que pudessem assessorá-lo naquela empreita. Desta forma trouxe para a cooperativa o diretor comercial e o assessor de RH da central de cooperativas que também presidia.

O diretor comercial assumiu o cargo de gerente comercial. Pessoa extremamente hábil tratou de montar uma estrutura de poder na cooperativa, a começar pelo setor de TI, onde conseguiu colocar uma pessoa de sua confiança, para desta forma, ter acesso sobre o sistema de controle da organização. Também influenciou a indicação da pessoa responsável pelo controle da chamada "conta cooperado", ou seja, além do acesso ao sistema de controle ele também tinha conhecimento de todas as movimentações financeiras dos cooperados. $\mathrm{O}$ assessor de $\mathrm{RH}$ continuou nesta função e também se mostrou extremamente dominador e influente, chegando a ser uma espécie de "guru" do novo presidente.

Como não dispunha de ampla visibilidade interna e apoio dos cooperados, e tinha a difícil tarefa de substituir um líder carismático, o novo presidente decidiu, sob influência de seus aliados, construir rapidamente uma imagem de pioneirismo e visão de futuro. Para construir esta imagem interna, ele decidiu pela implantação de ferramentas técnicas consideradas as melhores e pela associação do seu nome a elas. Foi neste momento que surgiu a idéia de se implementar um sistema ERP, que naquela época era considerada uma inovação, e que traria para a cooperativa o título de ser a primeira cooperativa brasileira a integrar todo o seu processo de gestão. Com estes objetivos, ele passou a utilizar um discurso baseado na adaptação da cooperativa à sociedade pós-industrial e na transformação da mesma em uma organização de aprendizagem, baseada na inovação e na mudança. 


\section{ESTUDO DE CASO: A DECISÃO E O PROCESSO DE IMPLEMENTAÇÃO DO SISTEMA ERP}

Para implementar suas idéias, o novo presidente deveria então negociá-las com as outras instâncias da administração. Entretanto, para tentar construir rapidamente uma imagem gerencial positiva, associando o seu nome à informatização da organização, o novo presidente decidiu, sem um estudo prévio sobre as necessidades do sistema organizacional, implementar o mais rapidamente possível o ERP - Entreprise Resource Planning.

Os sistemas do tipo ERP são sistemas de informação que permitem a integração de toda a gestão de uma empresa, agilizando os processos de decisão por meio da melhoria do acesso e compartilhamento das informações. Estes sistemas permitem ainda que o desempenho da empresa seja constantemente monitorado (Caldas e Wood, 1999 e 2003). A implementação desses sistemas implica em um amplo processo de mudança organizacional, já que tem conseqüências sobre o modelo de gestão, a arquitetura organizacional, os processos de negócios, nas relações de poder etc. Como colocam Wood e Caldas, os esforços de implementação destes sistemas são normalmente marcados pela atmosfera de urgência, sem o devido cuidado com todos os aspectos desta complexa mudança, o que leva muitas vezes ao fracasso destas empreitadas.

Neste processo de decisão, podemos apontar algumas particularidades. Ao levantar a bandeira da informatização, o novo presidente teve alguns aliados: o gerente comercial, o gerente administrativo e o assessor de RH. Entretanto, formou-se rapidamente um grupo opositor, formado por quadros da área industrial. Estes indivíduos, liderados pelo gerente industrial, acabaram não participando da reunião que decidiu pela compra do sistema, pois o gerente industrial naquela época estava fora do país.

O gerente industrial era uma pessoa com sólida formação profissional em engenharia, oriunda do quadro de cooperados e conhecida pela comunidade pelo seu pragmatismo técnico e senso ético. Foi um dos responsáveis pela construção do parque industrial da cooperativa e sempre participou das principais decisões da cooperativa nos tempos do antigo presidente. Pelo seu pragmatismo técnico questionou a viabilidade de se implantar o sistema ERP sem realizar uma reengenharia organizacional da cooperativa. A decisão de implantação do sistema ERP foi realizada a sua revelia, e por este motivo foi um critico feroz deste sistema e também forte opositor do novo presidente. Por ironia do destino, grande parte da customização do sistema teria que ser feita em módulos relacionados à área industrial (recebimento, classificação, limpeza, processamento, armazenagem e movimentação de grãos).

Sem que o conselho administrativo da cooperativa percebesse, o novo presidente assinou um contrato com uma empresa de consultoria. O contrato previa, inclusive, que caso o sistema ERP não funcionasse, a responsabilidade total seria da empresa contratante, ou seja, caso o sistema não fosse operacional, a cooperativa assumiria o prejuízo sozinha, sem poder responsabilizar a empresa de consultoria prestadora do serviço. De acordo com o contrato, o sistema seria implantado em duas fases. Em um primeiro momento, implementar-se-ia o sistema nas funções de suporte administrativo e também no controle das contas correntes dos cooperados e na recepção e controle dos estoques de cereais. Eram estas as áreas da cooperativa controladas pelos indivíduos aliados do novo presidente. Em uma segunda fase o sistema seria implementado nas atividades industriais e em outros controles financeiros específicos da atividade cooperada, as áreas controladas pelos opositores do projeto. $\mathrm{O}$ processo, entretanto, durou e custou muito além do previsto e gerou resistências na organização. $\mathrm{O}$ grupo ligado à área industrial, contrária à implementação do sistema e excluída da tomada de decisão, não cooperou efetivamente no processo de implementação. 
Os problemas se iniciaram logo no início do processo, com uma avaliação inadequada das características e necessidades da cooperativa agrícola. Apesar da grande experiência da empresa de consultoria encarregada do projeto, esta não possuía familiaridade com o setor agrícola. Desta forma, os técnicos responsáveis pela implementação do ERP subestimaram as dificuldades de customização deste sistema para uma cooperativa agro-industrial, que possui características organizacionais próprias. Desta forma, eles não realizaram nenhum estudo ou diagnóstico em profundidade, importando os sistemas padrão que possuíam, específicos ao setor indus trial, para a cooperativa agrícola.

A má-avaliação das especificidades desta organização ficou patente com a quantidade exorbitante de rotinas que acabaram sendo desenvolvidas na última hora a fim de adaptar-se um sistema típico de empresas industriais às práticas organizacionais da cooperativa. A maioria das empresas industriais e comerciais que utilizam este sistema desenvolve geralmente entre $10 \%$ e $15 \%$ de rotinas novas com esta linguagem. Este é o limite normal para a criação de novos códigos e procedimentos necessários no processo de customização do sistema e adaptação às necessidades do cliente específico. Todavia, no caso da cooperativa, chegourse ao extremo de se ter $60 \%$ das rotinas reescritas nesta linguagem, ou seja, para que o sistema padrão funcionasse, os técnicos tiveram que recriar seis vezes mais códigos do que o que seria normal, quase refazendo toda a programação. Estes fatos fizeram o processo de implantação atrasar, adicionando custos exorbitantes ao mesmo, uma vez que as horas de programação extra necessárias à customização do sistema eram responsáveis por um aumento significativo dos custos de produção.

Ao final de 1998, nas vésperas de eleições para o novo dirigente da cooperativa, o presidente impôs aos consultores que o sistema teria que estar funcionando em janeiro do ano seguinte. Mesmo que o sistema não funcionasse a contento, o presidente queria associar o seu nome a ele, com vistas ao processo eleitoral. Desta forma, o sistema acabou sendo implantado apenas parcialmente e somente o módulo financeiro funcionou adequadamente. Apesar da tentativa de construção de uma imagem interna positiva, os cooperados, representados pelo conselho de administração, não o reelegeram.

Em março de 1999 a nova diretoria eleita reavaliou imediatamente o projeto de implantação do ERP. Inicialmente tentou negociar com a empresa de consultoria uma solução aceitável para os problemas. A empresa de consultoria se propôs a terminar o sistema, mas com um grande custo adicional. Foi então contratada uma empresa de auditoria, que constatou imediatamente o excesso de rotinas na linguagem e os altos custos que este fato iria criar na manutenção do sistema. Diante deste quadro a nova direção resolveu abortar a implantação do ERP. A nova diretoria da cooperativa ingressou com uma ação judicial para anulação de algumas cláusulas contratuais, pedindo ressarcimento pelos prejuízos.

\section{ANÁl ISE DO CASO: PARADOXO CULTURAL NA GESTÃo DE PESSOAS}

Os atores sociais entrevistados mostraram que não tinham, na época da reeleição, conhecimento concreto dos dados detalhados sobre a implementação do ERP, uma vez que eles eram mantidos sob estrita confidencialidade pelo presidente. $\mathrm{O}$ que levou então o conselho de cooperados a não reeleger o presidente, a despeito dos esforços de associar a implantação do sistema ao seu nome e do fato de que os cooperados desconheciam o custo real do projeto e os problemas na implementação?

Para o Interacionismo Simbólico, os indivíduos exercem papéis nas organizações e se comunicam para construir o sentido comum de sua ação. A organização é considerada um conjunto de papéis e representações, em cujo contexto os indivíduos constroem e apreendem os significados socialmente compartilhados. Estes significados regulam a interação entre os indivíduos e lhes fornecem 
expectativas recíprocas em suas experiências cotidianas. Os significados socialmente compartilhados tornam habituais certos tipos de comportamentos em determinadas situações e interações sociais.

A maioria dos cooperados compartilhava valores participativos e democráticos que eram a essência da identidade coletiva, e estava imersa num contexto em que a confiança, a negociação e o consenso compunham o núcleo constitutivo dos processos sociais. É relevante discutirmos o conceito "nativo" tradicional de tomada de decisão. Durante os 27 anos de liderança carismática na organização, seus membros estavam inseridos em um contexto no qual a decisão era considerada um processo de construção coletiva do consenso. Através da influência e articulação política do líder, as decisões eram tomadas após um processo durante o qual os atores sociais relevantes eram sensibilizados para as questões em pauta e construíam as resoluções influenciando e sendo influenciados pelo líder. Nestes processos, nossas observações indicaram a importância da confiança entre os diversos atores sociais relevantes para a construção dos consensos. Mesmo que não participassem todos os indivíduos de todas as decisões, a confiança deveria ser mantida por meio de processos de decisão em que os atores relevantes exercessem plenamente sua margem de manobra em seus níveis de atuação no sistema social.

Podemos dizer que as premissas do modelo político de gestão de pessoas freqüentemente estruturam as relações sociais em contextos nos quais a negociação e o debate entre os atores sociais são as regras do sistema (Brabet, 1993; Wiazosky e Silva, 1999). Em contextos organizacionais marcados por estes padrões culturais, os indivíduos são percebidos como atores dotados de visões complementares da realidade e que participam e influenciam as mudanças. O líder deve buscar o consenso, integrando as visões e os interesses dos diferentes grupos políticos, visando a obtenção de uma solução negociada junto à direção da empresa (Beer e Walton et al. 1985; Brabet, 1993). A organização é um espaço de jogo estratégico entre estes atores sociais, no qual a negociação é vista como necessária à boa implantação das estratégias.

Percebe-se que os conflitos organizacionais narrados no caso foram decorrentes do processo de decisão liderado pelo novo presidente, no qual foi decidida a implementação do sistema ERP. Apesar da identificação da maior parte da organização com o conceito "nativo" de tomada de decisão descrito acima, nossas observações permitiram a identificação de duas subculturas na organização. Cada uma era caracterizada por visões diferentes acerca da condução da empreitada, e compartilhava conceitos distintos de tomada de decisão. $\mathrm{O}$ antagonismo entre estas duas subculturas ficou claro por ocasião das discussões sobre o projeto de informatização. Em uma atitude típica do "modelo instrumental de gestão de pessoas", o grupo político do novo presidente excluiu seus opositores do processo de decisão, que eram atores sociais relevantes neste processo, e implementou em regime de urgência o sistema, em uma atitude de imposição. Esta decisão quebrou as relações de confiança entre os indivíduos no sistema organizacional e os obrigou a trabalharem de acordo com critérios técnicos que lhes eram impostos de cima para baixo, sem a devida negociação para o consenso, como típica da cultural organizacional majoritária. Neste sentido, os demais atores sociais foram forçados a exercerem o estranho papel de meros executores de uma estratégia definida unilateralmente por um grupo diretivo.

O que aconteceu na cooperativa foi um paradoxo cultural na gestão de pessoas. Os estudos atuais sobre paradoxos organizacionais que partem dos princípios do Interacionismo Simbólico apontam fenômenos que atrapalham a construção de sentido comum pelo grupo organizacional e dificultam sua ação. Estes trabalhos mostram que os paradoxos na gestão de pessoas muitas vezes estão relacionados à existência simultânea de interpretações inconsistentes na mesma organização, resultado de leituras diferentes da realidade organizacional (Vasconcelos, 2003). No caso da cooperativa, a leitura da realidade 
organizacional feita pelo novo presidente e seu grupo permitiu-lhes legitimar uma mudança abrupta, autoritária, na qual se rompia com o presente em nome do progresso. Esta postura baseava-se na convicção individual e tecnocrática do novo presidente. Entretanto, no contexto da interação deste grupo com outros que compartilhavam outras convicções, a postura do novo presidente foi interpretada como uma ameaça ao sistema e à coletividade, gerando resistência e stress. Como coloca Jaime Júnior (2002), tratourse de uma clivagem interpretativa, interpretações inconsistentes ou contraditórias de um mesmo objeto devido a repertórios culturais distintos.

Podemos descrever a situação como a existência simultânea de duas interpretações incoerentes de uma mesma prática social: os atos do novo presidente. A primeira interpretação da realidade foi aquela do novo presidente e de seu grupo de influência. Eles assumiram que, por meio de suas ações, transmitiriam a imagem de competência e modernidade. A segunda interpretação foi aquela dos outros grupos organizacionais, segundo a qual as ações do novo presidente demonstravam seu caráter autoritário, não alinhado àquele sistema social, o que os incomodava (Vasconcelos, 2003; Lewis, 2000). Como definido por Eisenhardt, tratava-se da existência simultânea de leituras irreconciliáveis da realidade organizacional, que geraram padrões de conduta incoerentes: a atitude unilateral do presidente e os padrões de interação social na organização baseados na confiança e na negociação (Eisenhardt, 2000).

Podemos analisar o que aconteceu na cooperativa a partir de uma visão dialética de evolução do grupo social. Esta perspectiva analisa a construção social da realidade através do construto social, das contradições geradas por este, e da transformação do sistema social por meio da práxis. A abordagem de diferenciação implica na visão da organização como um complexo construto social formado pelo agrupamento de conjuntos de significados criados e recriados constantemente, segundo os quais os grupos de indivíduos dão sentido à sua experiência e organizam sua interação social. O paradoxo cultural na gestão de pessoas analisado é uma contradição que surge e influencia a ação dos indivíduos no contexto da dinâmica de interação entre os grupos organizacionais, ou subculturas. A hegemonia alternada de um ou outro grupo pode fazer com que determinadas interpretações sejam consideradas predominantes, o que não diminui entretanto a percepção de contradições e conflitos nas organizações. No caso estudado, o grupo organizacional do novo presidente, hegemônico durante seu mandato, conseguiu sustentar as suas interpretações entre os outros grupos organizacionais, mas sofreu as conseqüências do paradoxo cultural no momento em que sua hegemonia foi questionada, a época das eleições.

As contradições perceptivas impulsionam a práxis, que pode ser conceituada como o conjunto de atividades individuais e coletivas para a contínua reconstrução do sistema social (Hillmann, 2001), uma vez que subgrupos organizacionais podem se movimentar no sentido de questionar o sistema e as regras presentes e agir politicamente no sentido de modificá-las. A dinâmica de interação entre os grupos na cooperativa estudada impunha o confronto das interpretações divergentes da realidade organizacional no momento das eleições. Naquela ocasião, o grupo que representava os cooperados, hegemônico naquele momento, percebeu, ao analisar o agressivo processo de mudança organizacional, que seus interesses e valores poderiam estar ameaçados no contexto organizacional. Desta forma, este grupo resistiu a perder espaço no sistema social e reagiu de maneira coerente não reelegendo o novo presidente e seu grupo. 

CULTURAIS NA GESTÃO DE PESSOAS

Podemos considerar que a cultura organizacional influencia profundamente a maneira como as ações, atitudes e posturas dos atores sociais vão ser interpretadas e valorizadas no contexto organizacional. O desenvolvimento dos estudos sobre este tema caracteriza-se pelas suas múltiplas abordagens teóricas e metodológicas. Como apontam diversos autores, a abordagem hegemônica parte de um conceito integrador de cultura e se foca nas manifestações culturais que são interpretadas de maneira consistente entre os grupos. Nesta abordagem, os pesquisadores buscam construir visões consensuais da cultura na organização: esta seria o que é claro e compartilhado pelos membros da organização (Mascarenhas, 2002; Barbosa, 1999; Martin, 1992 e 2002). O conceito de cultura organizacional de Schein (1985), neste caso, é uma das referências mais utilizadas:

"se não há consenso, ou se há conflito ou se as coisas são ambíguas então, por definição, aquele grupo não tem uma cultura em relação àquelas coisas (...) o compartilhamento e consenso são centrais à definição, e não escolhas empíricas" (Schein, 1991, p. 248).

O estudo dos paradoxos culturais na gestão de pessoas, entretanto, requer um outro olhar sobre o tema. Como descreve Martin (2002), a abordagem de "diferenciação" é utilizada em pesquisas sobre a cultura organizacional cujo foco é a busca das manifestações culturais interpretadas de maneira inconsistente entre os grupos organizacionais. Como coloca Jaime Júnior (2002), os indivíduos nas organizações não devem considerar que seus discursos e ações simbólicas possuem um significado único. Quando nos posicionamos no ângulo de sua recepção, percebemos que estas mensagens são interpretadas sempre a partir do repertório cultural do receptor, que as significam de acordo com seus conjuntos de representações. Para termos uma idéia da complexidade desta questão, basta pensarmos que os indivíduos e grupos identificam-se, antes de se tornarem membros de uma organização, com crenças religiosas, afiliações políticas, origens étnicas etc., além de estarem inseridos de maneira desigual na estrutura social. Esta constatação nos faz perceber a diversidade de interpretações possíveis em um contexto organizacional, ou a existência de subculturas, grupos organizacionais que compartilham padrões de significação distintos. Tem-se aí outro conceito de cultura organizacional, que a considera a união de diversas subculturas que podem conviver se reforçando mutuamente, em conflito cons tante ou independentemente. Nesta abordagem a ambigüidade é incluída como parte da complexa realidade cultural da organização (Martin, 1992 e 2002).

A idéia de paradoxo cultural na gestão de pessoas é útil para compreendermos o que aconteceu na cooperativa estudada. A análise do caso sugere que o paradoxo cultural é um elemento importante para a análise das dinâmicas de interação entre grupos organizacionais no contexto da evolução dos construtos sociais, o que tem implicações no entendimento de processos políticos e sócio-culturais. Se associarmos as idéias do interacionismo simbólico a uma visão dialética da evolução social, apresentada no início deste artigo, percebemos que as contradições e inconsistências entre as subculturas de um sistema organizaciomal podem impulsionar a práxis e proporcionar a energia para a constante reconstrução deste sistema social. Neste sentido, os paradoxos culturais são constitutivos dos sistemas sociais, pois influenciam na sua contínua evolução. Logo, entender as percepções paradoxais dos grupos em organizações e descrevê-las dentro deste referencial pode ser uma perspectiva muito rica ao pesquisador. É possível acompanhar estas percepções e descrever como evoluem as subculturas dos diversos grupos em relação à organização, no processo dialético de evolução. 


\section{NOTAS}

${ }^{\mathrm{i}}$ Trata-se de um recurso metodológico. O tipo ideal é uma tendência refinada, e não uma realidade empiricamente comprovada. Segundo Weber, "obtém-se um tipo ideal mediante a acentuação unilateral de um ou vários pontos de vista, e mediante o encadeamento de grande quantidade de fenômenos isoladamente dados, difusos e discretos, que se podem dar em maior ou menor número ou mesmo faltar por completo, e que se ordenam segundo os pontos de vista unilateralmente acentuados, a fim de se formar um quadro homogêneo de pensamento" (Weber, 1997, p. 106).

\section{REFERÊNCIAS BIBLIOGRÁFICAS}

ALVES M.A. Vire-se, Zé Ninguém! A difícil construção da identidade em organizações pós-fordistas. In: ENCONTRO ANUAL DA ASSOCIAÇÃO NACIONAL DOS PROGRAMAS DE PÓSGRADUAÇÃO EM ADMINISTRAÇÃO, 26º 2002, Florianópolis. Anais... Florianópolis: Anpad, 2002.

BARBOSA, L. Igualdade e meritocracia, a ética do desempenho nas sociedades modernas. Rio de Janeiro: Fundação Getúlio Vargas, 1999.

BARBOSA, A. C. Q.; FERRAZ, D. E.; LOPES, D. Competências nas organizações: O discurso e a prática na gestão de pessoas. In: ENCONTRO ANUAL DA ASSOCIAÇÃO NACIONAL DOS PROGRAMAS DE PÓS-GRADUAÇÃO EM ADMINISTRAÇÃO, 2002, Salvador. Anais... Salvador: Anpad, 2002.

BEER, M. et al. Human resource management. Glencoe: Illinois Free Press,.1985.

BLAU, P.; SCOTT, W. Organizações formais. São Paulo: Atlas, 1970.

BRABET, J. Repenser la gestion des ressources humaines. Paris: Economica, 1993.

CALDAS, M. P.; WOOD JR, T. Modas e modismos em gestão: Pesquisa exploratória sobre adoção e implementação de ERP. In: ENCONTRO ANUAL DA ASSOCIAÇÃO NACIONAL DOS PROGRAMAS DE PÓS-GRADUAÇÃO EM ADMINISTRAÇÃO, 23ํ, 1999, Foz do Iguaçu. Anais... Foz do Iguaçu: Anpad, 1999.

CALDAS, M. P.; WOOD JR, T. A parte e o todo - reducionismo e pensamento complexo na adoção de sistemas empresariais. In: RUBEN, G.; WAINER, J.; DWYER, T. Informática, organizações $e$ sociedade no Brasil. São Paulo:Editora Cortez, 2003.

CAPELLE, M.; BRITO, M. Relações de poder no espaço organizacional: O caráter disciplinar das práticas de gestão de pessoas em uma organização de desenvolvimento de software. In: ENCONTRO ANUAL DA ASSOCIAÇÃO NACIONAL DOS PROGRAMAS DE PÓS-GRADUAÇÃO EM ADMINISTRAÇÃO, 2002, Salvador. Anais... Salvador: Anpad, 2002.

DAVIS, A. S.; MARANVILLE, S. J.; OBLOJ, K. The paradoxical process of organizational transformation: Propositions and a case study. Research in organizational change and development $\mathrm{n}$. 10, p. 275-314, 1997.

EISENHARDT, K. Paradox, spirals, ambivalence: The new language of change and pluralism. The Academy of Management Review, v. 25, n. 4, p. 703-706, 2000.

ENRIQUEZ, E. L'organisation en analyse. Paris: P.U.F., 1991. 
FARIA, J.; MENEGUETTI, F. As novas formas de controle psicológico no trabalho. In: ENCONTRO ANUAL DA ASSOCIAÇÃO NACIONAL DOS PROGRAMAS DE PÓS-GRADUAÇÃO EM ADMINISTRAÇÃO, 25, 2000, Campinas. Anais... Campinas : Anpad, 2000.

FESTINGER, L. A Theory of cognitive eissonance. New York: Prentice-Hall, 1957.

FISCHER, M. Da antropologia interpretativa à antropologia crítica. In: Anuário Antropológico - 83. Rio de Janeiro: Tempo brasileiro, 1985.

FLEURY, M. O simbólico nas relações de trabalho. In: FLEURY, M.; FISCHER, R. Cultura e poder nas organizações. São Paulo: Editora Atlas, 1996.

FROST, P.; ROBINSON, S. The toxic handler: Organizational hero and casualty. Harvard Business Review, v. 77, p. 97-106, 1999.

GEERTZ, C. A interpretação das culturas. Rio de Janeiro: Livros Técnicos e Científicos, 1989.

HEGEL, F. La Phénomenologie de l'Esprit. Paris: Aubier, 1941.

HILLMANN, K. Diccionario Enciclopédico de Sociologia. Barcelona: Editorial Herder, 2001.

JAIME JR., P., Um texto, múltiplas interpretações: antropologia hermenêutica e cultura organizacional. Revista de Administração de Empresas, v. 42, n. 4, 2002.

KETS DE VRIES, M. Organizational paradoxes: Clinical approaches to management. New York: Routledge, 1995.

LEWIS, M. Exploring paradox: Toward a more comprehensive guide. The Academy of Management Review, v. 25, n. 4, p. 760-776, 2000.

MASCARENHAS, A. Etnografia e cultural organizacional - uma contribuição da antropologia à administração de empresas. Revista de Administração de Empresas, v. 42, n. 2, p. 88-94, 2002.

MARTIN, J. Cultures in organizations - three perspectives. Oxford: Oxford University Press, 1992.

MARTIN, J. Organizational culture - mapping the terrain. Thousand Oaks : Sage Publications, 2002.

MERTON, R. Social theory and social structure. Glencoe: Free Press, 1950.

MOTTA, F.; VASCONCELOS, I. Teoria Geral da Administração. São Paulo: Thomson_Learning Pioneira, 2002.

MYEONG-GU, S. E.; CREED, D. Institutional contradictions, praxis and institutional change: A dialectical perspective. Academy of Management Review, v. 27, n. 2, p. 222-247, 2002.

POOLE, M. S.; VAN DE VEN, A.H. Using paradox to build management and organization theories. The Academy of Management Review, v. 14, p. 562-578, 1989.

RADA, A.; VELASCO, H. La lógica de la investigación etnográfica. Madrid: Editorial Trotta, 1997. 
SABELIS, I. Temporal paradoxes: Working with cultural diversity in organizations. In KOOT, W.; Sabelis, I.; Ybema, S. (eds) Contradictions in context: Puzzling over paradoxes in contemporary organizations. Amsterdam: VU University Press, 1996.

SCHEIN, E. Organizational culture and leadership. San Francisco : Jossey-Bass, 1985.

SCHEIN, E. What is culture? In: FROST, P. et al. (org.). Reframing organizational culture. London: Sage, 1991.

SELZNICK, P. TVA and the grass roots. Berkley: University of California Press, 1955.

SIMON, H. Administrative Behavior. New York: Doubleday, 1947.

SIMON, H. A behavioral model of rational choice. Quartely Journal of Economies, v. LXIX, p. 99$118,1955$.

SMIRCICH, L. Organizations as shared meanings. In PONDY, L. (ed.) Organizational Symbolism. Greenwich: JAl, 1983a.

SMIRCICH, L. Studing organizations as cultures. In MORGAN, G. (eds). Beyond method: strategies for social research. Bervely Hilís: Sage, 1983b

THOMPSON, J. Ideologia e cultura moderna. Petrópolis: Editora Vozes, 1995.

TROOTINGS, P.; GUSTAVSEN, B.; HETHY, L. (eds) New forms of work organization in Europe. New Brunswick: Oxford Transation Publishers, 1989.

VASCONCELOS, I.. A dialética da mudança: Uma análise crítica do conceito de paradoxos organizacionais. Relatório de pesquisa apresentado ao NPP - Núcleo de Pesquisas e Publicações da FGV-EAESP. São Paulo:FGV-EAESP, 2003.

VASCONCELOS, I.; MOTTA, F.; PINOCHET, L. Tecnologia, paradoxos organizacionais e gestão de pessoas. Revista de Administração de Empresas, v. 43, n. 2, 2003.

VASCONCELOS, I..; VASCONCELOS, F. ISO 9000, consultants and paradoxes: A sociological analysis of quality assurance and human resource techniques. In: ENCONTRO ANUAL DA ASSOCIAÇÃO NACIONAL DOS PROGRAMAS DE PÓS-GRADUAÇÃO EM ADMINISTRAÇÃO, 25\%, 2000, Campinas. Anais... Campinas: Anpad, 2000.

VASCONCELOS, I.; VASCONCELOS, F. Gestão de pessoas e identidade social: Um estudo crítico. Revista de Administração de Empresas, v. 42, n. 1, 2002.

WEBER, M. A "objetividade" do conhecimento nas ciências sociais. In: COHN, G. Weber, coleção grandes cientistas sociais. Editora Ática, 1997.

WIAZOWSKI, B. A.; SILVA, C.A.B.; Coordenação de cadeias produtivas: Uma aplicação de sistemas dinâmicos ao agronegócio da carne bovina. Anais do II Congresso da SBI-Agro - Agrosoft 99.

Campinas, 1999. 


\section{ORGANIZAÇÕES - PARADOXOS CULTURAIS NA GESTÃO DE PESSOAS: CULTURA E CONTEXTO EM UMA \\ COOPERATIVA AGRO-INDUSTRIAL \\ Isabella Vasconcelos - André Ofenhejm Mascarenhas - Roberto M. Protil}

\section{Isabella Vasconcelos}

Professora do departamento de Administração da FGV-EAESP. Doutora em Administração

E-mail: ivasconcelos@yahoo.com

Endereço: Av. 9 de Julho, 2029, $9^{\mathrm{a}}$ andar Bela Vista - São Paulo - SP, 01313-902.

Interesses de pesquisa: administração de recursos humanos e teoria das organizações.

\section{André Ofenhejm Mascarenhas}

Doutorando e Mestre em Administração pela FGV-EAESP.

E-mail: andremascar@gvmail.br

Endereço: Al. Ribeirão Preto, 438, ap. 702 Bela Vista - São Paulo - SP, 01331-000.

Interesses de pesquisa: administração de recursos humanos, simbolismo nas organizações, teoria das organizações.

\section{Roberto Max Protil}

Professor titular do Programa de Pós-Graduação em Administração da PUCPR. Doutor e Mestre em Administração.

E-mail: protil@ppgia.pucpr.br.

Endereço: Rua Imaculada Conceição, 1155 Curitiba - PR, 80215-901.

Interesses de pesquisa: modelagem empresarial, processo decisório e sistemas de informação e de apoio à decisão no agronegócio. 